\begin{tabular}{|c|c|c||c|c|c|c|c|}
\hline JOURNAL OF EDUCATION, SCIENCE AND HEALTH - JESH \\
Revista de Educação, Ciência e Saúde \\
DOI: https://www.doi.org/10.52832/jesh.v2i1.76 \\
Home page: www.jeshjournal.com.br \\
e-ISSN: $2763-6119$
\end{tabular}

\title{
O PERFIL DAS PESSOAS EM SITUAÇÃO DE RUA ATENDIDAS PELA CASA DO ANDARILHO
}

\author{
THE PROFILE OF PEOPLE IN STREET SITUATION SERVICED BY CASA DO ANDARILHO
}

EL PERFIL DE LAS PERSONAS EN SITUACIÓN DE LA CALLE ATENDIDAS POR CASA DO ANDARILHO

\author{
Mauricio de Oliveira Silva ${ }^{1 *(1)}$; Alana Cardoso dos Santos ${ }^{2}(\mathbb{D})$
}

\begin{abstract}
${ }^{1}$ Doutorando em Agroecologia e Desenvolvimento Territorial (UNIVASF). Mestre em Ciências Ambientais (UESB). Especialista em Educação e Direitos Humanos (Alfa América). Especialista em Serviço Social e Saúde Coletiva (Faculdade Estratego). Licenciado em Ciências Biológicas (UESB). Professor da rede municipal de Vitória da Conquista -BA (SMED), Vitória da Conquista, Bahia, Brasil. ${ }^{2}$ Graduanda em Serviço Social pela Universidade Tiradentes (UNIT) polo Vitória da Conquista - BA, Vitória da Conquista, Bahia, Brasil.

*Autor correspondente: m.osilva@hotmail.com
\end{abstract}

Recebido: 11/01/2022 | Aprovado: 04/02/2022| Publicado: 11/02/2022

\begin{abstract}
Resumo: A organização da sociedade atual sobre a égide capitalista gera diversas desigualdades, dentre elas, há a exclusão de pessoas que passam a não ter direitos básicos e acabam tendo que viver nas ruas, são os andarilhos. O presente artigo tem como objetivo identificar o perfil dos usuários da população em situação de rua, atendidos pela Casa do Andarilho, localizada em Vitória da Conquista, Bahia, em tempos de pandemia da Covid-19 e a partir disso conhecer os motivos que levam as pessoas a viverem nas ruas e como estas são conduzidas a se abrigarem nessa instituição. Para coleta de dados, foi utilizado a técnica de análise documental, observação in loco e questionário on-line via Google Forms, contendo 15 perguntas. Por meio da pesquisa foi possível perceber que 80\% dos usuários são do sexo masculino, vivem permanentes no abrigo, tem entre 51 a 60 anos, não são todos conquistenses, foram encaminhados pela rede socioassistencial e tem como motivações de serem andarilhos, uso de substâncias ilícitas, distúrbios psíquicos, conflitos familiares e outros. A pesquisa ainda mostrou que o serviço social dentro da instituição desenvolve trabalhos de prevenção à Covid-19 com os usuários, com orientações quanto a lavagem das mãos, uso de máscaras, vacinação e manutenção do distanciamento social. Nota-se a necessidade de pesquisas mais amplas para entender o perfil das pessoas em situação de rua no Brasil, bem como buscar medidas mitigadoras e soluções para essa questão.
\end{abstract}

Palavras-chave: Desigualdade social. Pobreza. Serviço social.

Abstract: The organization of current society under the capitalist aegis generates several inequalities, among them, there is the exclusion of people who do not have basic rights and end up having to live on the streets, they are the wanderers. This article aims to identify the profile of the users of the homeless population, served by Casa do Andarilho, located in Vitória da Conquista, Bahia, in times of the Covid-19 pandemic and from that to know the reasons that lead the people to live on the streets and how they are led to take shelter in this institution. For data collection, we used the technique of document analysis, in loco observation and an online questionnaire via Google Forms, containing 15 questions. Through the research, it was possible to perceive that $80 \%$ of the users are male, live permanently in the shelter, are between 51 and 60 years old, are not all conquerors, were referred by the social assistance network and have as motivations to be wanderers, substance use illicit acts, psychic disorders, family conflicts and others. The research also showed that the social service within the institution develops work to prevent Covid-19 with users, with guidelines on hand washing, use of masks, vaccination and maintenance of social distance. There is a need for broader research to understand the profile of homeless people in Brazil, as well as to seek mitigating measures and solutions to this issue.

Keywords: Social inequality. Poverty. Social service.

Resumen: La organización de la sociedad actual bajo la égida capitalista genera varias desigualdades, entre ellas, la exclusión de personas que no tienen derechos básicos y terminan teniendo que vivir en la calle, son los vagabundos. Este artículo tiene como objetivo identificar el perfil de los usuarios de la población sin hogar, atendidos por la Casa do Andarilho, ubicada en Vitória da Conquista, Bahía, en tiempos de la pandemia de Covid-19 y, a partir de eso, conocer las razones que llevan a las personas a vivir. en las calles y cómo son llevados a refugiarse en esta institución. Para la recolección de datos, se utilizó la técnica de análisis de documentos, observación in loco y un cuestionario en línea a través 
de Google Forms, que contiene 15 preguntas. A través de la investigación se pudo percibir que el 80\% de los usuarios son del sexo masculino, viven permanentemente en el albergue, tienen entre 51 y 60 años, no todos son conquistadores, fueron referidos por la red de asistencia social y tienen como motivaciones ser deambulantes, consumo de sustancias ilícitas, trastornos psíquicos, conflictos familiares y otros. La investigación también arrojó que el servicio social dentro de la institución desarrolla un trabajo de prevención de la Covid-19 con los usuarios, con lineamientos sobre lavado de manos, uso de mascarillas, vacunación y mantenimiento de la distancia social. Existe la necesidad de una investigación más amplia para comprender el perfil de las personas sin hogar en Brasil, así como para buscar medidas de mitigación y soluciones a este problema.

Palabras-clave: Desigualdad social. Pobreza. Servicio social.

\section{INTRODUÇÃO}

Em tempos atuais, observamos como a sociedade evolui, cria novas tecnologias, ideias, comportamentos, se moderniza e se adapta aos novos acontecimentos, no entanto, um aspecto antigo ainda se encontra presente nesta sociedade moderna, que é uma parte de seus cidadãos viverem na rua em situação de risco, sem uma alimentação adequada, sem higiene básica, dentre outros aspectos degradantes. Todos esses aspectos são vistos em quase todo o mundo, inclusive no Brasil, onde, em certos casos a pobreza acaba por se tornar um fator influenciador para que os números de cidadãos em situação de rua aumentem cada vez mais (Mendes, Ronzani \& Paiva, 2019).

“A desigual distribuição de bens sociais, a discriminação, o desrespeito às diferenças, a incerteza, a involução de valores não são anomalias, mas constituintes do pensamento globalizado e do processo econômico em curso" (Costa, 2005, p. 1). Mendonça (2006, p. 11) caracteriza os "moradores de rua" como sendo "[...] qualquer pessoa que, sem moradia, pernoita, nos logradouros da cidade, nos albergues ou qualquer outro lugar não destinado à habitação", e dentre estes estão os andarilhos, o elemento de estudo desse artigo. Os "andarilhos", são as pessoas que se deslocam pelos bairros ou de cidade em cidade, geralmente sozinhos, não se vinculando a nada, a referência que se intitulam é simplesmente que estão "no trecho" (Costa, 2005).

Os motivos que levam essas pessoas a abandonarem seus lares são os mais diversos, até o momento não foi possível determinar uma causa específica para que tais pessoas se abriguem nas ruas, porém, ainda existe um raio de esperança com a implementação de políticas públicas voltadas para este público (Balieiro, Soares \& Vieira, 2017). Uma das opções disponíveis dentro da sociedade que ajudam à essas pessoas, são os abrigos, associações voltadas para estas causas, a atuação do serviço social na sociedade, que visa garantir os direitos desses cidadãos, possibilitando a reinserção dessas pessoas de volta aos seus lares e a sua comunidade, onde este, terá a oportunidade de recomeçar, como afirmam Bove \& Figueiredo (2015, p. 23)

O primeiro passo que foi dado no sentido de transformar a realidade descrita até aqui, foi apostar num elemento fundamental: o protagonismo. Entender a pessoa em situação de rua como sujeito de direitos, não apenas como alvo de caridade, foi fundamental. Toda mudança dessa realidade passa, necessariamente, pela transformação individual e coletiva, que somente as próprias pessoas em situação de rua podem fazer.

A partir dessa premissa, é possível compreender que as pessoas em situação de rua sofrem com vários problemas, desde o preconceito a complicações com relação ao saneamento, segurança, dentre outros fatores agravantes, no entanto, é importante que uma análise seja elaborada sobre este cenário e suas características na 
tentativa de identificar possíveis soluções para os envolvidos nessa situação (Bove \& Figueiredo, 2015; Balieiro, Soares \& Vieira, 2017; Mendes, Ronzani \& Paiva, 2019).

A sociedade dentro desse contexto capitalista convive com diferentes questões sociais acentuado pelo processo de globalização, pobreza e fragilidade das relações humanas, baseado na falta ou ineficiência do Estado em propor políticas públicas eficazes. Nesse mundo cada vez mais individual e que os sonhos das pessoas são pensados individualmente tem-se a sociedade egocêntrica que é uma construção social da era capitalista, apontada mesmo nos sonhos de paraíso (Silva, 2020). Como Cortella (2015) afirma:

\begin{abstract}
para não poucos, o sonho de paz e vida feliz é poder retirar-se para uma ilha paradisíaca, distante de tudo e afastada do maior número possível de humanos e humanas, isto é, isolar-se: ilha, condomínio fechado, alto da montanha, praia privativa, local inacessível; no máximo, horrorizar-se ou alegrar-se virtualmente com o que acontece com a humanidade, mas, sem chegar muito perto" (Cortella, 2015, p. 34).
\end{abstract}

Silva (2020) explica que o egocêntrico vive tanto por si mesmo que não percebe o meio ambiente que o cerca, é manipulado pela imagem, pela égide do capitalismo. Não mais é um ser, mas passa a ter, quem tem é, quem não tem não é. E nesse jogo de cada um por si, muitas das vezes, pessoas em situação de rua são invisibilizadas e esquecidas. A situação de rua é algo que vem sendo abordado por diferentes administrações públicas, tendo em vista a complexidade e a necessidade de intervenção de diversos segmentos que procuram obter uma forma de reduzir ao máximo essa questão de vulnerabilidade social (Abreu \& Salvadori, 2015).

Os cidadãos em situação de rua convivem constantemente com a não garantia e acesso aos direitos sociais adquiridos pela Constituição Federal de 1988, constituindo-se assim como sujeitos a margem de uma sociedade que exclui e estigmatiza (Abreu \& Salvadori, 2015). Tendo isso em vista, esta pesquisa tem como objetivo identificar o perfil dos usuários da população em situação de rua, atendidos pela Casa do Andarilho, localizada em Vitória da Conquista, Bahia, em tempos de pandemia da doença do coronavírus (Covid-19) e a partir disso conhecer os motivos que levam as pessoas a viverem nas ruas e como estas são conduzidas a se abrigarem nessa instituição.

\title{
2 MATERIAL E MÉTODOS
}

A metodologia utilizada para desenvolver este estudo consiste em pesquisa bibliográfica, descritiva e quali-quantitativa. A pesquisa bibliográfica, seria um plano estratégico que conduz um estudo científico, na tentativa de explicar, discutir um assunto, temática ou problema, através de referências de livros, artigos, revistas, dentre outros componentes deste universo bibliográfico (Michel, 2015).

De acordo com Gil (2008) a pesquisa descritiva, objetiva descrever as características de determinadas populações ou fenômenos. Uma de suas peculiaridades está na utilização de técnicas padronizadas de coleta de dados, tais como o questionário e a observação sistemática.

\section{1 Área de Estudo e Público-alvo}

A realização deste trabalho ocorreu na instituição Associação Comunitária Cristo Liberta - Casa do Andarilho, localizada na cidade de Vitória da Conquista, que está a aproximadamente $518 \mathrm{~km}$ de distância da 
capital Salvador, é a terceira maior cidade da Bahia que conta com uma população aproximada em 2021 de 343 mil habitantes, representada por 51,8\% mulheres e 48,2\% homens (IBGE, 2010). Esta instituição teve sua fundação com o objetivo de amparar pessoas que foram excluídas da sociedade, que precisam de abrigo e demais cuidados.

A Casa do Andarilho, uma das primeiras instituições filantrópicas a ser instalada em Vitória da Conquista em parceria com a sociedade civil, faz-se manter vivo o sonho de poder ajudar os mais necessitados, aqueles que foram abandonados por seus familiares, além de promover ações que podem contribuir para o desenvolvimento profissional daqueles que fazem uso dos serviços dessa instituição. Estima-se que essa instituição dentre seus 22 anos de atuação, tenha atendido mais de 45 mil pessoas, mesmo com muita dificuldade em obter os recursos necessários, principalmente com relação aos alimentos, pois, estima-se que por mês gasta-se cerca de cinco toneladas de alimentos.

O público-alvo atendido nesta unidade de acolhimento é o adulto, de ambos os sexos, em situação de rua ou em trânsito, caracterizado por pessoas em situação de extrema vulnerabilidade social e risco pessoal, a maioria está desempregada ou não tem condições de se empregar, são dependentes de substâncias psicoativas, pessoas com transtornos mentais, egressos do sistema prisional ou foragidos da justiça, apresentam histórico de violência física e/ou sexual. Os vínculos familiares dessas pessoas encontram-se fragilizados ou totalmente rompidos, sendo que muitos não têm perspectiva de mudança de sua condição. Nesse sentido, a Organização Não-Governamental (ONG) Casa do Andarilho oferece abrigo, alimentação e atendimento de saúde para as pessoas em situação de rua.

\subsection{Coleta de dados}

Para coleta de dados, foi utilizado a técnica de análise documental, observação in loco e questionário. A técnica utilizada para coleta dos dados se deu através de uma busca com as palavras-chave "população em situação de rua", "pessoas em situação de rua e preconceito", “andarilhos" e "morador de rua" nas bases da Scientific Electronic Library Online (Scielo) e do Google Acadêmico, este último termo mesmo não sendo o adequado é/foi muito utilizado para realizar pesquisas sobre pessoas em situação de rua.

Também aplicou-se um questionário semiestruturado on-line via Google Forms, contendo 15 perguntas abertas e fechadas (Quadro 1), de modo que, este foi enviado para a diretora da Casa do Andarilho que assinou o termo de consentimento livre e esclarecido (TCLE) e disponibilizou informações das fichas dos usuários, seguindo todos os aspectos éticos sem nenhuma possibilidade de identificação individual das pessoas atendidas. Ademais, foram realizadas três visitas para observar o ambiente (suas acomodações, conhecer os usuários, etc.) seguindo as normas de prevenção a transmissão da Covid-19. Para a análise dos dados, foi utilizado a técnica de análise de conteúdo, buscando compreender o significado dos dados coletados.

Quadro 1. Questionário aplicado com a diretora da Casa do Andarilho. 
1. No período da pandemia quantos usuários estão na casa do andarilho?

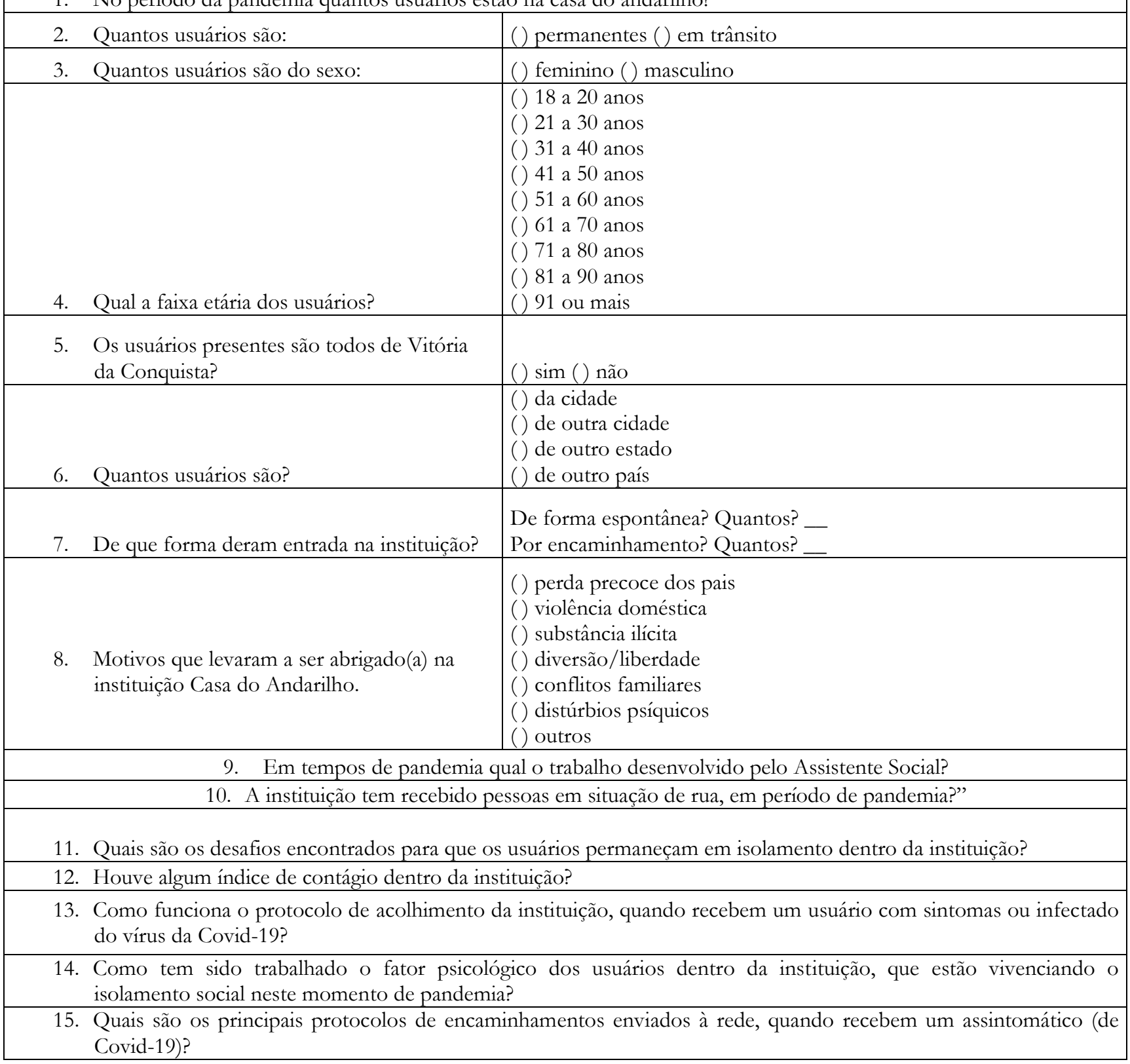

Fonte: dados da pesquisa, 2021.

\section{RESULTADOS E DISCUSSÃO}

Os resultados e discussão foram separados em: a) população em situação de rua e o preconceito; b) análise do público atendido pela instituição e c) ações desenvolvidas na instituição para melhor atender o público. Dessa forma, os dados levantados por meio de cada fase da pesquisa serão debatidos por categorias.

\subsection{População em situação de rua e o preconceito}

Compreendendo melhor as pessoas em situação de rua, apresentaremos informações fundamentais acerca dessa população que se encontra pertencente em um contexto social de desigualdades a partir dos dados levantados por meio da pesquisa bibliográfica e das palavras-chave utilizadas. "Este fenômeno social constitui uma síntese de múltiplas determinações, cujas características, mesmo com variações históricas, o tornam um 
elemento de alta relevância na composição da pobreza nas sociedades capitalistas.” (Silva, 2009, p. 91).

$\mathrm{Na}$ busca por compreender melhor o perfil das pessoas em situação de rua, o Ministério do Desenvolvimento Social e Combate à Fome (MDS), desenvolveu uma pesquisa com o objetivo de coletar o quantitativo de pessoas que sobrevivem nessa situação (Brasil, 2008). A pesquisa foi realizada em 71 cidades de todo o país, abrangendo 23 capitais e 48 outras cidades com população superior a 300 mil habitantes, entre agosto de 2007 e março de 2008, foram identificadas 31.922 pessoas maiores de 18 anos, em situação de rua. Estes foram definidos por um grupo populacional que apresenta: condição de pobreza, desemprego estrutural, migração, rompimento de vínculos familiares, dentre outros aspectos que se fazem presentes no dia a dia dessas pessoas.

Percebe-se um aumento significativo da população que sobrevive nessa condição, através de um monitoramento realizado pelo Sistema Único de Assistência Social (Censo SUAS), onde, estima-se que existiam no ano de 2015, 101.854 pessoas em situação de rua no Brasil (Natalino, 2016). No que diz respeito ao crescimento da população em situação de rua, no Brasil, é perceptível uma expansão da superpopulação relativa no mundo e no Brasil, particularmente em sua forma flutuante, devido à redução de postos de trabalho na indústria o que ajuda a explicar a expansão do fenômeno.

Somados a essa situação de desigualdade, durante a pandemia do coronavírus (Covid-19) iniciada no ano de 2020, os medos e incertezas foram muitas e como demonstram Silva \& Ferreira (2020), o isolamento social afetou as emoções e relações afetivas das pessoas que estavam em isolamento (ou não). Esses autores destacam que um dos maiores medos durante a pandemia foi a crise econômica gerada pelo fechamento do comércio, que consequentemente gerou demissões em massa, afetando principalmente a classe mais pobre do país. Nesse sentido, como apontam Silva \& Ferreira (2020), a pandemia pode ter ampliado o número de pessoas em situação de rua, já que afeta o orçamento das famílias mais pobres e, consequentemente, leva pessoas ou mesmo famílias a viverem nas ruas.

Conforme Maia, Sanches \& Vasconcellos (2019), a Política Nacional de Inclusão social da população em situação de rua, identifica que este grupo, mesmo na sua diversidade, tem algumas características em comum, sendo caracterizado como um grupo populacional heterogêneo que exibe em comum a pobreza, quebra de vínculos familiares, existência de um processo de desfiliação social pela deficiência de trabalho assalariado e das coberturas sucedidas deste vínculo, sem moradia convencional aceitável e restando a rua como espaço social, de moradia e sustento. Nesse sentido, compreende-se que, a globalização e o avanço da tecnologia, tem alcançado diferentes sociedades contemporâneas, onde este, tem gerado um desfecho negativo, relacionado na reprodução de desigualdades sociais e na falta de garantias para grande parte da população. A desigual distribuição de bens sociais, a discriminação, o desrespeito às diferenças, a incerteza, a involução de valores não são desequilíbrios, mas sim, pertencentes do pensamento globalizado e do processo econômico vigente.

Maia, Sanches e Vasconcellos (2019) confirmam essa premissa, quando afirma que, situações como: condição de pobreza, desemprego estrutural, migração, dependência química, estado de conflitos familiares, entre outros, permeiam cidadãos exclusos das estruturas convencionais da sociedade e possuem menos que o 
indispensável para atender às necessidades básicas do ser humano e vivem no limite da miséria ou pobreza absoluta.

Os preconceitos têm sua sustentação em bases afetivas e irracionais, amparadas na desinformação, na ignorância, no moralismo, no conservadorismo e também no conformismo. Algumas definições, por serem configuradas em uma determinada formação sociocultural, poderão até explicar atitudes de discriminação, mas nunca justificá-las (Machado, 2014).

Os preconceitos são juízos provisórios refutados pela ciência e por uma experiência cuidadosamente analisada, mas que se conservam inabalados contra todos os argumentos da razão. Nem um nem vários preconceitos bastam para fazer com que um cidadão seja "imoral", isso depende essencialmente da relação entre a individualidade e a totalidade das consequências e motivações do preconceito.

Nesse sentido, é possível compreender o preconceito, como algo abstrato que se caracteriza sempre como moralmente negativo. Porque todo preconceito impede a autonomia do homem, ou seja, diminui sua liberdade relativa diante do ato de escolha, ao deformar e consequentemente, estreitar a margem real de alternativa do indivíduo. Heller (1989) nos diz que, os preconceitos se formam a partir de uma modalidade de discriminação sobre aqueles que direcionam suas vidas de forma diferente do dito "normal". Nesse sentido, a autora citada afirma que "o desprezo pelo outro, a antipatia pelo diferente, são tão antigos quanto a própria humanidade".

Contudo, pode-se afirmar, que a discriminação é o resultado das relações sociais que estabelecemos através da reprodução de valores que, por vezes, incorporamos ao nosso cotidiano. O sentimento de culpa, expressa nos relatos da população em situação de rua, acentua o sentimento de fracasso, ocasionando o fechamento do sujeito sobre si mesmo e a perda de referências. O que ao nosso ver, caracterizam a falta ou ineficiência das políticas de assistência social para este grupo.

\subsection{Análise do público acolhido pela Casa do Andarilho}

Por meio do processo de coleta dos dados dos registros de usuários da instituição, um total de 20 pessoas em situação de rua são atendidos na Casa do Andarilho. O perfil desses sujeitos estão apresentados na tabela 1. Podemos verificar que dos usuários, $60 \%$ são moradores permanentes, $80 \%$ são homens, $65 \%$ tem entre 51 a 60 anos, não são todos de Vitória da Conquista, com 25\% conquistenses, 55\% de outras cidades e $25 \%$ de outros estados do Brasil, 95\% foram encaminhados pela rede socioassistencial, 30\% foram viver em situação de rua devido o uso de drogas ilícitas, 20\% por distúrbios psíquicos como esquizofrenia, 15\% por conflitos familiares e $35 \%$ por outros motivos, desde escolha por viver dessa forma, desemprego, dentre outros. 
Tabela 1 - Perfil dos cidadãos em situação de rua atendidos na casa do Andarilho, em Vitória da Conquista - BA e motivos que os influenciaram.

\begin{tabular}{|c|c|c|c|}
\hline VARIÁVEL & CATEGORIA & $\mathrm{N}^{\circ}$ & $\%$ \\
\hline $\begin{array}{l}\text { No período de pandemia, } \\
\text { quantos usuários estão } \\
\text { presentes na } \\
\text { Instituição? }\end{array}$ & 18 a 80 anos & 20 & 100 \\
\hline Quantos usuários são? & $\begin{array}{l}\text { permanentes } \\
\text { em trânsito }\end{array}$ & $\begin{array}{c}12 \\
8\end{array}$ & $\begin{array}{l}60 \% \\
40 \%\end{array}$ \\
\hline \multirow[t]{2}{*}{ Quantos usuários são do sexo } & masculino & 16 & $80 \%$ \\
\hline & feminino & 4 & $20 \%$ \\
\hline $\begin{array}{l}\text { Qual a faixa etária dos } \\
\text { usuários da instituição? }\end{array}$ & $\begin{array}{r}18 \text { a } 20 \text { anos } \\
21 \text { a } 30 \text { anos } \\
31 \text { a } 40 \text { anos } \\
41 \text { a } 50 \text { anos } \\
51 \text { a } 60 \text { anos } \\
61 \text { a } 70 \text { anos } \\
71 \text { a } 80 \text { anos } \\
81 \text { a } 90 \text { anos } \\
91 \text { ou mais }\end{array}$ & $\begin{array}{l}00 \\
01 \\
01 \\
01 \\
13 \\
03 \\
01 \\
00 \\
00\end{array}$ & $\begin{array}{c}0 \% \\
5 \% \\
5 \% \\
5 \% \\
65 \% \\
15 \% \\
5 \% \\
0 \% \\
0 \%\end{array}$ \\
\hline Os usuários são todos de Vitória da & $\operatorname{sim}$ & & \\
\hline Conquista? & não & $\mathrm{x}$ & --- \\
\hline Quantos usuários são de fora do & do município & 05 & $25 \%$ \\
\hline \multirow[t]{3}{*}{ Município/estado/país } & outra cidade & 11 & $55 \%$ \\
\hline & outro estado & 05 & $25 \%$ \\
\hline & outro país & 00 & $0 \%$ \\
\hline \multirow{2}{*}{$\begin{array}{l}\text { De que forma osusuários deram } \\
\text { entrada na instituição? }\end{array}$} & de forma espontânea & 01 & $5 \%$ \\
\hline & $\begin{array}{c}\text { por encaminhamento da rede } \\
\text { socioassistencial }\end{array}$ & 19 & $95 \%$ \\
\hline Motivos que influenciaram os & Perda precoce dos pais & 00 & $0 \%$ \\
\hline \multirow[t]{6}{*}{ usuários à irem para as ruas? } & Violência doméstica & 00 & $0 \%$ \\
\hline & Substância Ilícita & 06 & $30 \%$ \\
\hline & Diversão/liberdade & 00 & $0 \%$ \\
\hline & Conflitos familiares & 03 & $15 \%$ \\
\hline & Distúrbio psíquico & 04 & $20 \%$ \\
\hline & Outros & 07 & $35 \%$ \\
\hline
\end{tabular}

Fonte: Dados da Pesquisa, 2021.

Os dados coletados estão de acordo com o decreto n 7.053 de 23 de dezembro de 2009 que Institui a Política Nacional para a População em Situação de Rua e seu Comitê Intersetorial de Acompanhamento e Monitoramento que considera

população em situação de rua o grupo populacional heterogêneo que possui em comum a pobreza extrema, os vínculos familiares interrompidos ou fragilizados e a inexistência de moradia convencional regular, e que utiliza os logradouros públicos e as áreas degradadas como espaço de moradia e de sustento, de forma temporária ou permanente, bem como as unidades de acolhimento para pernoite temporário ou como moradia provisória (Brasil, 2009, on-line). 
Estes dados nos mostram que a questão relacionada a reiserção dessas pessoas demandam políticas públicas mais eficientes e necessitam de um grupo multidisciplinar de assistência social, pois, há a necessidade de trabalhos voltados a prevenção ao uso de drogas, apoio psicológico, jurídico e de sáude. Bove \& Figueiredo (2015, p. 16) consideram que:

"a população em situação de rua, em sua trajetória de vida, perdeu a garantia de domicílio regular; ao
morar na rua, tudo é provisório: onde dormir, onde se alimentar, como sobreviver. Muitas vezes, dormir
no mesmo local todas as noites é correr risco de violência, o que leva as pessoas a improvisar espaços que
ofereçam maior proteção."

Instituições do terceiro setor como a Casa do Andarilho oferecem um lugar com condições mínimas humanizadas para essas pessoas, mas o Estado é o maior responsável por não levar direitos humanos básicos a seus cidadãos, como a moradia, a saúde, o emprego e condição digna de vida. Por esse modelo, de um Estado negligenciador, há uma parcela mal intencionada ou mal informada da sociedade mundial e, em particular, da sociedade brasileira, nos últimos anos que vem atribuindo funções salvacionistas a um conjunto (em constante crescimento) de entidades, conhecidas pela sigla, em língua portuguesa, ONG ou Organização nãogovernamental (Montaño, 2002). O que pode levar a mais desmontes nas políticas públicas de atenção as pessoas em situação de rua no Brasil, gerando mais omissão dos órgãos públicos sobre a vida de seus cidadãos.

A realidade de muitas pessoas viverem nas ruas é algo que observamos todos os dias, é uma situação triste e que aumenta cada vez mais, o que requer uma atenção maior do serviço social para com essas pessoas, principalmente nos dias atuais de 2020, onde estamos vivendo em meio a uma pandemia, necessitando de todo o cuidado possível para não se contaminar e não contaminar outras pessoas.

De acordo com o estudo de Natalino (2016) estimava-se que cerca de 101 mil pessoas vivem em situação de rua no Brasil, reunidas em municípios de grande porte, diante disso, percebe-se como esses números vem aumentando desde os dados levantados no ano de 2008, e com isso vários outros problemas começam a surgir, como a pandemia da Covid-19, que contribuiu ainda mais para o aumento da população que sobrevive nas ruas. Uma nova estimativa da população de rua indica, por sua vez, que, em março de 2020, tínhamos cerca de 222 mil pessoas em situação de rua (Silva, Natalino \& Pinheiro, 2020).

Para Balieiro, Soares \& Vieira (2017), é algo comum em nosso cotidiano encontrarmos pessoas vivendo em situação de rua na cidade na qual habitamos. Nesse sentido, entende-se por pessoa em situação de rua, aqueles sujeitos que evadiram de seus lares, que não possuem moradia própria, que pernoitam, em albergues, casas de apoio, em construções abertas pela cidade, que servem como moradia temporária para essas pessoas.

Mendes, Ronzani \& Paiva (2019) discutem que essa população se caracteriza como heterogênea por possuir diversos motivos para habitarem as ruas. No entanto, um aspecto frequente observado dentre as pessoas em situação de rua, é o uso de substâncias psicoativas, pois, o uso excessivo de tais substâncias, acabam por gerar vários problemas, dentre estes, o conflito familiar, a violência física e verbal, e até mesmo problemas de saúde influenciando no cidadão o sentimento de abandonar seu lar fixo e ir em busca de abrigo nas ruas.

Nesse sentido, os espaços de acolhimento são um dos principais lugares onde essas pessoas habitam, contudo, ainda existem aqueles que ficam vagando pelas ruas que não conseguem discernir em qual lugar devem 
ir para se abrigar, pois muitas vezes foram influenciados por problemas mentais à irem pra rua (Bezerra et al., 2015), o quais são chamados de andarilhos ou "trecheiros".

Ainda de acordo Balieiro, Soares \& Vieira (2017), os motivos influenciadores podem ser os mais diversos e provocar forte influência nas pessoas em situação de rua, dessa maneira, observa-se que muitos acabam mudando da sua cidade natal em busca de abrigo, de outras oportunidades, ou apenas para se distanciar ainda mais dos conflitos com seus familiares e/ou pessoas próximas.

Dessa forma, é possível observar com base nos dados levantados, que a parcela da população estudada (55\%) são de outra cidade, o que acaba por confirmar o que Balieiro, Soares \& Vieira (2017) dizem em seu estudo. A partir dessa premissa, é possível observar que quase a totalidade do público entrevistado (95\%) foi encaminhado para a instituição através da rede socioassistencial, pois através dessa rede é possível de forma organizada manter um censo dos cidadãos que adentram no município, bem como aqueles que já habitam nas ruas, proporcionando aos mesmos um lar temporário, sem riscos à sua segurança e saúde, principalmente nos tempos atuais, onde estamos enfrentando a pandemia da Covid-19.

Com o avanço da pandemia pelo mundo e principalmente no Brasil, vários foram os problemas surgidos, e com eles, ações preventivas estão sendo desenvolvidas na tentativa de controlar tais problemas, nesse sentido, um olhar para as pessoas nessa situação foi/deveria ser intensificada em todas as esferas públicas, privadas e do terceiro setor a fim de ofertar direitos básicos a essas pessoas.

Entre as medidas de ajuda, é possível citar a distribuição de itens de higiene, distribuição de alimentos, medidas de transferência direta de renda, distribuição de equipamentos de proteção individual (EPI) dentre outras medidas que visam ajudar aos grupos mais vulneráveis em destaque as pessoas que vivem nas ruas (Silva, Natalino \& Pinheiro, 2020).

A pandemia do Covid-19 é uma infecção respiratória aguda causada pelo coronavírus SARS-CoV-2, potencialmente grave, de elevada transmissibilidade e de distribuição global, com uma potencial influência no aumento da desigualdade social, já que afeta diretamente os postos de trabalho, a economia, a saúde, a educação, as relações sociais e, consequentemente, outros aspectos da vida das pessoas, pois sua prevenção necessita do distanciamento social, o que pode invisibilizar mais ainda as pessoas em situação de rua.

\subsection{Ações desenvolvidas na Casa do Andarilho e o papel dos profissionais envolvidos}

Conforme o desenvolvimento desta pesquisa, pôde-se acompanhar as intervenções realizadas pela instituição e equipe técnica, onde se estabeleceu um paradoxo em relação a atual situação de pandemia da Covid19 e a obrigatoriedade de uma intervenção às pessoas acolhidas pela instituição com a instrução de hábitos cotidianos indispensáveis à sobrevivência humana, não só durante o período emergencial que se vive.

Dessa forma, a partir da técnica de observação in loco, foi possível constatar através das apresentações realizadas pelas trabalhadoras (a enfermeira, a assistente social e a psicológa) da instituição, que há um trabalho de educação para a promoção do bem-estar e da saúde. Foram observadas aulas e atividades de recreação durante as visitas, algumas em forma de palestras e videoaulas para orientar os usuários sobre informações 
eficazes acerca da prevenção da trasmissão da Covid-19, como o uso de máscaras, álcool em gel, lavagem das mãos, vacinação e distanciamento social, além de aulas de dança e recreação com um educador físico voluntário.

A partir desse contexto, é possível confirmar o fato quando a entrevistada responde a seguinte pergunta:

P-Em tempos de pandemia qual o trabalho desenvolvido pelo Assistente Social?

E- Neste momento, foram desenvolvidas atividades de educação e cuidados na prevenção, disposição de inclusão e atualização do Cadastro Único na promoşão da disposição do Auxílio Emergencial e continuação nas atividades rotineiras como contatos com a rede assistencial e família na promocão de vínculos, encaminhamentos diversos e entrada em Benefícios Assistenciais (BPC) etc.

Com base nas ações mencionadas pela entrevistada, é possível compreender o quão importante é o atendimento do serviço social, pois, segundo Couto (2015), é necessário fugir do pragmatismo, de métodos empíricos que alimentam as análises apressadas que são desenvolvidas no campo da assistência social.

Nesse sentido, é preciso fugir de armadilhas, que define esse campo como o de um adestramento da população usuária, construtor de modelos ideais de famílias, de serviços, dentre outros aspectos que acabam por não considerar as condições de vida. É necessário que exista a garantia de um serviço de qualidade, que conecta as necessidades sociais da população lhes proporcionando usufruir dos seus direitos.

Em outro dado momento da pesquisa, foi feito a seguinte pergunta:

P. "A instituição tem recebido pessoas em situação de rua, em perído de pandemia?" Onde teve-se como resposta a seguinte: E- "Não". Nesse sentido, foi feita a seguinte indagação:

P-Quais são os desafios encontrados para que os usuários permaneçam em isolamento dentro da instituição?

E- Trabalho de conscientização constante, suspensão da rotatividade da população de rua, proibição da saída do público e minimização de visitantes, higienização constante e uso dos protocolos de distanciamento, máscaras e uso de álcool em gel.

Nesse sentido, percebe-se a tamanha importância das ações desenvolvidas dentro da instituição para que os usuários da mesma, possam se sentir protegidos e possivelmente seguros do vírus. Possuir condições de acessar água e produtos de higiene corporal e domésticos são fatores importantes na balança dos riscos, bem como a presença de vínculos relacionais de proteção.

Sabe-se ainda que a ameaça da Covid-19 não é apenas viral, pois ela é coproduzida pelas condições desiguais de vida da população brasileira, o que se chega a pensar que se isso é verdade, as pessoas em situação de vulnerabilidade, por suas condições de vida, estão muito mais suscetíveis ao vírus (Dutra \& Smiderle, 2020).

Apesar da Covid-19 se disseminar democraticamente, as taxas de mortalidade não são democráticas, e diferentes populações estão sujeitas a maiores e menores riscos. Ter privilégio de estar isolado no conforto de uma casa, ter acesso à serviços de saúde, a medicamentos e a uma alimentação saudável, a água, a produtos de higiene corporal e doméstica são fatores que pesam na balança dos riscos e pode fazer diferença entre a vida e a morte (Souza, 2012).

Nesse sentido, foi feito a seguinte pergunta:

P. "Houve algum indice de contágio dentro da instituição?" Tendo como resposta: E- "Não". Mais adiante foi feita outra indagação: P- "A instituição recebeu algum usuário com sintomas da Covid-19?" Onde teve-se como respostas a seguinte: E- "Não". Mais adiante foi questionado:

P- Como funciona o protocolo de acolbimento da instituição, quando recebem um usuário com sintomas ou infectado do vírus da Covid- 
19 ?

E- Não recebemos ninguém com sintomas ou infectados.

É notável que em estudo realizado por Maciel, Silva e Souza (2020, p. 222), "No contexto da pandemia, percebe-se mais a atuação da necropolítica, aliada aos processos de desumanização e objetificação dos corpos de grupos mais vulneráveis do que proposta certeiramente eficazes." E apontam que "considerando a população em situação de rua, não se limita a uma territorialidade específica. A gestão sanitária será certamente um desafio para os pós pandemia."

A partir dessa premissa buscou-se saber alguns aspectos relacionados ao fator psicológico dos cidadãos acolhidos, desse modo, foi feito a seguinte questão:

P-Como tem sido trabalhado o fator psicológico dos usuários dentro da instituição, que estão vivenciando o isolamento social neste momento de pandemia?

E-Com a disposição de atividades recreativas, palestras educativas, ludoterapia, passeio terapêutico, escuta individualizada e de grupo.

$\mathrm{Na}$ Casa do Andarilho, essas atividades citadas pela entrevistada são desenvolvidas pelas profissionais assistente social e psicóloga, que têm formações voltadas a lidar com tais situações. Dutra \& Smiderle (2020), reforçam a importância desses profissionais ao afirmar que percebe-se a grande importância que existe na colaboração entre assistentes sociais e psicólogos, pois os mesmos, acabam por realizar um importante trabalho a partir das necessidades que lhes é apresentada. Pois, como foi apresentada nas falas dos entrevistados o assistente social visa cuidar tanto do bem-estar como das questões de encaminhamento social e prevalência dos direitos, enquanto que o psicólogo visa também o bem-estar físico e mental, principalmente em uma situação tão delicada advinda da Covid-19, onde, o número de visitas caem, não é possível sair da instituição, não é possível receber novos integrantes, o que culmina em prejudicar a saúde mental, caso esta não seja estimulada.

$\mathrm{Na}$ intenção de afirmar o que Dutra \& Smiderle (2020) dizem sobre o bem-estar e sobre as ações do assistente social, é possível observar quando é questionado sobre:

P-Quais são os principais protocolos de encaminhamentos enviados à rede, quando recebem um assintomático?

E- Não recebemos assintomáticos, os poucos casos que aceitamos neste período de Pandemia na Instituição só foi permitido após isolamento de 15 dias e devidamente testado.

Em um outro momento no desenvolvimento desta pesquisa, foi possível observar a intervenção do assistente social, visando a promoção, a integração e a capacitação de cada interno. Estes, são aspectos que se caracterizam como um dos objetivos principais e profissionais dessa classe que busca cada vez mais, trazer qualidade nos serviços ofertados à estas pessoas. Dessa forma, fica claro que o papel do assistente social não é só prover os direitos e encaminhamentos aos serviços sociais da rede, mas também, proporcionar junto com as instituições, atividades educativas e recreativas que estimulem o lado social dessas pessoas que vivem em situação de rua.

\section{CONSIDERAÇÕES FINAIS}

Com a realização desta pesquisa, foi possível obter um perfil das pessoas em situação de rua acolhidas pela Casa do Andarilho, que são 60\% moradores permanentes, $80 \%$ do sexo masculino, maioria com idade entre 
51 a 60 anos, atende andarilhos da cidade, de outras cidades e de outros estados, que foram encaminhados, em sua maioria, pela rede socioassistencial e tem como motivos de estarem em situação de rua o uso de drogas ilícitas, distúrbios psíquicos, conflitos familiares e outros.

A pesquisa ainda mostrou que o serviço social dentro da instituição desenvolve trabalhos de prevenção à Covid-19 com os usuários, com orientações quanto a lavagem das mãos, uso de máscaras, vacinação e manutenção do distanciamento social e atividades recreativas que ajudam a vencer os dias desgastantes gerados pela pandemia da Covid-19. Com esses dados, buscamos provocar nova discussão a partir de uma instituição estudada, demonstrando que há necessidade de pesquisas mais amplas para entender o perfil das pessoas em situação de rua no Brasil, bem como buscar medidas mitigadoras e soluções para essa questão.

\section{Conflitos de interesses}

Os autores declaram que não há conflitos de interesse. Todos os autores estão cientes da submissão do artigo.

\section{Contribuições dos autores}

Todos os autores contribuíram de maneira substancial na realização do artigo.

\section{REFERÊNCIAS}

Abreu, D.; \& Salvadori, L. V. (2015). Pessoas em situação de rua, exclusão social e rualização: reflexões para o serviço social. In: Seminário Nacional de Serviço Social, Trabalho e Política Social. Universidade Federal de Santa Catarina, Florianópolis, 1-8. https://seminarioservicosocial2017.ufsc.br/files/2017/05/Eixo 3 188.pdf

Balieiro, E. O.; Soares, C. P. D.; \& Vieira, E. A. (2017) Morador de rua: Causas, entraves e serviços ofertados, Revista Temporalis, 17(34), 333-353. https://doi.org/10.22422/2238-1856.2017v17n34p333-353

Bezerra, I. H. P.; Filho-Mâcedo, I.; Costa, R. J. L. M.; Sousa, V. J.; \& Carvalho, M. V. G. (2012). População em situação de rua: um olhar da enfermagem sobre o processo saúde/doença. Enfermagem Revista, 18(1), 3-14.

Bove, C.; \& Figueiredo, G. (2015). População em situação de rua. Coleção Caravana de Educação em Direitos Humanos. Brasília: Edição da Secretaria de Direitos Humanos da Presidência da República - SDH/PR e Faculdade Latino-americana de Ciências Sociais - Flacso Brasil.

Brasil. (2008). Política nacional para inclusão social da população em situação de rua. Brasília - DF. Obtido em: http://www.recife.pe.gov.br/noticias/arquivos/2297.pdf.

Brasil. (2009). Decreto n 7.053 de 23 de dezembro de 2009. Institui a Política Nacional para a População em Situação de Rua e seu Comitê Intersetorial de Acompanhamento e Monitoramento, e dá outras providências. Obtido em: http://www.planalto.gov.br/ccivil 03/ ato2007-2010/2009/decreto/d7053.htm

Cortella, M. S. (2015). Não nascemos prontos! Provocações filosóficas. (19ed.) Petrópolis: Vozes.

Costa, A. P. M. (2005). População em situação de rua: contextualização e caracterização. Revista Virtual Textos \& Contextos, 4(4), 1-15. https://revistaseletronicas.pucrs.br/ojs/index.php/fass/article/view/993

Couto, B. R. (2015). Assistência social: direito social ou benesse? Revista Serviço Social \& Saúde, 1(124), 665-677. 
Dutra, J.; \& Smiderle, J. (2020). Água e saneamento na pandemia da Covid-19 - desafio e oportunidade. Revista Conjuntura Econômica, 74(4), 50-51. https://ceri.fgv.br/sites/default/files/2020-04/saneamento joisa juliana.pdf

Gil, A. C. (2008). Métodos e técnicas de pesquisa social. (6 ed.) São Paulo: Atlas S.A.

Heller, A. (1989). O cotidiano e a história. (3 ed.) São Paulo: Paz e Terra.

IBGE. (2010). Brasil: Babia: Vitória da Conquista. Instituto Brasileiro de Geografia e Estatística. Obtido em: https://cidades.ibge.gov.br/brasil/ba/vitoria-da-conquista/pesquisa/23/25124

Machado, T. (2014). População em situação de rua e sociedade: uma relação marcada por preconceito e estigma. Florianópolis SC (Trabalho de Conclusão de Curso, Universidade Federal de Santa Catarina). https://repositorio.ufsc.br/bitstream/handle/123456789/133048/TCC\%20THAYSE\%20\%20Machado.pdf?se quence $=1 \&$ is Allowed $=\mathrm{y}$

Maciel, L. L.; Silva, M. G.; \& Souza, A. A. M. (2020). A população em situação de rua diante da pandemia: um estudo de caso ampliado entre São José dos Campos/SP e São Paulo/SP. Revista Nacional de Gerenciamento de Cidades, 8(63), 205-225.

Maia, L. F. S; Sanches, A. M; \& Vasconcellos, C. (2019). Pessoa em situação de rua e desigualdade social: uma questão de políticas públicas. Revista Recien. 9(28):146-154.

Mendes, K. T.; Ronzani, T. M.; \& Paiva, F. S. (2019). Se essa rua falasse: uma análise sobre estigma, pobreza e uso de drogas nas trajetórias de sujeitos em situação de rua. Juiz de Fora: Editora UFJF.

Mendonça, G. C. (2006). Sentidos subjetivos de moradores de rua frente ao futuro. Campinas: Pontifícia Universidade Católica de Campinas.

Michel, M. H. (2015). Metodologia e pesquisa cientifica em ciências sociais: um guia prático para acompanhamento da disciplina e elaboração de trabalhos monográficos. (3. ed.) São Paulo: Atlas.

Montaño, C. (2002). Terceiro setor e questão social; crítica ao padrão emergente de intervenção social. São Paulo: Cortez.

Natalino, M. A. C. (2016). Estimativa da população em situação de rua no Brasil. Instituto de Pesquisa Econômica Aplicada. http://repositorio.ipea.gov.br/bitstream/11058/7289/1/td 2246.pdf

Silva, M. L. L. (2009). Trabalho e população em situação de rua no Brasil. São Paulo: Cortez.

Silva, M. O. (2020). Percepção socioambiental de visitantes do Parque Municipal Serra do Periperi no Nordeste Brasileiro. (Mestrado em Ciências Ambientais, Universidade Estadual do Sudoeste da Bahia), Itapetinga - BA.

Silva, M. O.; \& Ferreira, E. S. (2020). Percepção sobre o isolamento social devido ao coronavírus (Covid-19) em Vitória da Conquista - BA. In: Tavares, T. R. P.; Medeiros, L. H. C. (Org.) Ciências da saúde no Brasil: contribuiçōes para enfrentar os desafios atuais e futuros (p. 23-39). Campina Grande: Editora Amplla.

Silva, T. D.; Natalino, M.; \& Pinheiro, M. B. (2020). Instituto de Pesquisa Econômica Aplicada. População em situação de rua em tempos de pandemia: Um levantamento de medidas municipais emergenciais, 74, Nota técnica. 7-18.

Souza, R. (2012). Politicas sociais. Indaial: UNIASSELVI. 